\title{
Aa. Vv., «Revue de littérature comparée», Littératures et écrivains de Tunisie
}

\section{Veronica Amadessi}

\section{(2) OpenEdition}

1 Journals

\section{Edizione digitale}

URL: http://journals.openedition.org/studifrancesi/7734

DOI: 10.4000/studifrancesi.7734

ISSN: 2421-5856

\section{Editore}

Rosenberg \& Sellier

\section{Edizione cartacea}

Data di pubblicazione: 1 décembre 2009

Paginazione: 674-675

ISSN: 0039-2944

\section{Notizia bibliografica digitale}

Veronica Amadessi, «Aa. Vv., «Revue de littérature comparée», Littératures et écrivains de Tunisie», Studi Francesi [Online], 159 (LIII | III) | 2009, online dal 30 novembre 2015, consultato il 09 janvier 2021. URL: http://journals.openedition.org/studifrancesi/7734 ; DOI: https://doi.org/10.4000/studifrancesi.7734

Questo documento è stato generato automaticamente il 9 janvier 2021.

\section{(c) (i) $\odot$}

Studi Francesi è distribuita con Licenza Creative Commons Attribuzione - Non commerciale - Non opere derivate 4.0 Internazionale. 


\title{
Aa. Vv., «Revue de littérature comparée», Littératures et écrivains de Tunisie
}

\author{
Veronica Amadessi
}

\section{NOTIZIA}

«Revue de littérature comparée», Littératures et écrivains de Tunisie, juillet-septembre 2008, n. 327, pp. 279-410.

1 Questo volume della «RLC» esplora il panorama letterario tunisino dai secoli più antichi all'epoca contemporanea. Il tema che riunisce i vari articoli è quello della coesistenza di lingue e culture diverse, che si rispecchia nelle questioni del bilinguismo, dell'interculturalità e del mélange. La prefazione di Pierre BRUNel e Ghazi KARMAOUI è seguita da una riflessione del poeta Abdelaziz КАСЕM, incentrata sulla condizione dello scrittore diviso tra due lingue, che cerca di avvicinarsi all'altro pur conservando le proprie tradizioni (rappresentate dal poeta Chabbi). Kacem parla anche del rinnovamento letterario che ha avuto luogo in Tunisia, grazie alle traduzioni e alle riviste, e si definisce un «homme de deux rives»: in quanto tale, egli rivendica la sua doppia appartenenza ed elogia le letterature comparate, terreno di scambio e di incontro di culture diverse. Il contributo che segue, di Nizar BEN SAAD, dedica alcuni spunti di riflessione agli scrittori tunisini che si trovano in bilico tra la cultura francese e quella tunisina, e che scrivono nella lingua dell'Altro. Maalouf, Chraïbi, Meddeb, sono solo alcuni di questi intellettuali che si sono posti il problema dell'identità: l'articolo si basa sulle interessanti teorie di Mansour M’Henni, contenute nel suo saggio De la transmutation littéraire au Maghreb (2002). Ghazi KARMAOUI analizza invece la letteratura prodotta da ebrei tunisini di espressione francese: i racconti brevi di Véhel, Ryvel et Danon fanno infatti riferimento all'ambiente socioculturale del quartiere israelita di Tunisi. Attraverso una descrizione degli spazi più importanti dei testi (il quartiere 
ebraico ed il cimitero), Karmaoui analizza la «hantise des espaces fermés» che caratterizza i personaggi delle novelle. La donna, figura centrale, assicura la trasmissione delle tradizioni e la Bibbia appare spesso nel testo sotto forma di riscrittura. La conclusione è che, all'interno di questo panorama ricchissimo, l'espressione dell'alterité sembra essere rifiutata. Ali ABASSI si concentra sul tema femminile, con un corpus di testi assai ampio e articolato. Passando attraverso cliché, studi psicanalitici e critica, Abassi dimostra che la letteratura tunisina francofona ritrae spesso le figure femminili tramite luoghi comuni; l'articolo sottolinea inoltre che esistono differenze tra gli autori, soprattutto tra uomini e donne, e che la scrittura femminile muta di pari passo alla questione dell'identità. Kais HAMMAMI si inserisce in questo panorama variegato ritornando alle origini della produzione intellettuale tunisina, attraverso la figura di Sant'Agostino. Ciò che interessa l'autore è la percezione dell'avvenire negli scritti agostiniani, in particolare nelle Confessioni. Agostino critica l'idea di destino, che non considera un'idea cristiana, bensì un inno all'antichità legata al fatum. Mettendo l'uomo al centro della propria storia, la filosofia agostiniana esplora la memoria ed il ricordo facendoli diventare incarnazione del presente. Si attiva così l'idea dell'uomo artefice del cambiamento e della storia, che si svilupperà poi nella filosofia occidentale a partire dal secolo xvII.

2 Dopo questo excursus sull'antichità, Pierre BRUNEL si concentra invece su uno scrittore più vicino al mondo contemporaneo, Mario scalesi. Di origini maltesi ed italiane, il poeta effettua continui riferimenti all'eredità greco-latina, con particolare insistenza sugli eroi epici, sui luoghi omerici senza dimenticare le allusioni dantesche. Le influenze bibliche non mancano, così come i riferimenti a Rimbaud. Scalesi evidenzia quindi una formazione ed una sensibilità divise tra diverse culture, lingue ed epoche. Samir MARZOUKI dedica il suo intervento alla figura di un romanziere arabofono, Béchir Khraief, i cui personaggi lottano contro un mondo opprimente. Il protagonista di Barg ellil (1961) è in effetti uno schiavo che lotta per non farsi schiacciare dalla società; senza avere l'illusione di vincere la battaglia contro la schiavitù il protagonista riesce, grazie alla propria furbizia, ad ottenere ciò che gli era negato. Marzouki dimostra che l'interesse del romanzo risiede in un atteggiamento che esalta i valori della società che l'ha prodotto. Hager HILA analizza un racconto di Salah Garmadi, Le Cireur, caratterizzato dal fatto di essere scritto sotto il segno dell'oralità. Il registro popolare della lingua è infatti integrato a quella che Hila definisce «écriture vocale». L'articolo si propone innanzitutto di individuare «des éclats de voix» e di sottolineare le tensioni contraddittorie dello spazio enunciativo e la lotta tra le forze antagoniste che le varie espressioni orali contraddistinguono. Denise BRAHIMI dimostra, nella sua analisi di Nous, décolonisés, che il linguaggio ricercato d'Hélé Béji non è un ornamento retorico: al contrario, si tratta di una scrittura sottile, in cui il pronome di prima persona plurale fa rientrare il soggetto che parla all'interno di un gruppo. La questione centrale è sapere se questo nous include sempre il je, o se le due istanze possono separarsi. Brahimi analizza quindi con molta acutezza il gioco dei pronomi in Hélé Béji, e conclude che due tipi di je (je e Je) entrano nel testo. Infine, Samia KASSAB-CHARFI indaga sulle modalità di scrittura di Colette Fellous, scrittrice tunisina di origini israelite emigrata in Francia, la cui «syntaxe-cinéma» si avvicina a quella di Marguerite Duras e di Nathalie Sarraute. I molteplici spazi urbani descritti provocano infatti un sentimento di étrangeté e di inbetweenness che caratterizza molti autori francofoni del Maghreb. Fellous sembra 
cercare «une histoire inscrite dans l'architecture même de la ville» ed è in tal senso molto ricca di immagini della molteplicità in relazione ai luoghi geografici. 